\title{
Diretrizes curriculares para o ensino da ética na graduação em enfermagem*
}

\author{
Curriculum guideline for teaching ethics in undergraduate nursing program
}

Directivas curriculares para la enseñanza de la ética en el pregrado en enfermería

\section{Heliane Moura Ferreira1', Lais Helena Ramos²}

\begin{abstract}
RESUMO
Este artigo apresenta a reflexão das autoras sobre os aspectos filosóficos, sociais e psicopedagógicos que devem sustentar o ensino da ética/ bioética para o desenvolvimento moral dos alunos de Enfermagem durante a graduação. Mostra a necessidade de planejamento e sistematização do ensino da ética/bioética nos currículos de graduação em Enfermagem para que possibilitem ao aluno tomar decisões nos mais variados contextos do processo de trabalho em saúde de forma autônoma e reflexiva. As autoras ainda propõem algumas diretrizes para o ensino da ética nos Cursos de Graduação em Enfermagem: Transversalidade do Ensino da Ética/Bioética; Valores/Virtudes/Atitudes éticas a serem desenvolvidas pelos alunos; Fundamentação do ensino da ética/bioética em referenciais consistentes e docentes capacitados; Métodos e Estratégias ativas de ensino-aprendizagem; Processo participativo na construção do ensino transversal da ética/bioética.
\end{abstract}

Descritores: Ética; Bioética; Programas de graduação em Enfermagem/ética ; Diretrizes; Educação em enfermagem/ética; Ensino

\begin{abstract}
This article discusses relevant philosophical, social, psychological, and pedagogical aspects that must guide the teaching of ethics/bioethics principles to undergraduate nursing students. There is a need to plan and use a systematic approach in teaching Ethics/Bioethics in the undergraduate nursing program in order to facilitate students' critical thinking and decision making in a variety of situations. The article also proposes an outline for teaching on ethics/bioethics in undergraduate nursing programs. This outline consists of: ethics/bioethics as a transversal subject; values, virtue, and ethical attitudes that students must develop; fundamentals of ethics/bioethics consistent with qualified faculty members, the use of methods and strategies student-centered; and, participative process in the construction of transversal teaching of ethics/bioethics.
\end{abstract}

Kewords: Ethics; Bioethics; Education, nursing, undergraduate nursing program; Guideline; Education; Teaching

\section{RESUMEN}

En este artículo se presenta la reflexión de las autoras sobre los aspectos filosóficos, sociales y psicopedagógicos que deben sustentar la enseñanza de la ética/bioética para el desarrollo moral de los alumnos de Enfermería durante el Pregrado. Muestra la necesidad de planificación y sistematización de la enseñanza de la ética/bioética en los currículos del Pregrado en Enfermería que posibiliten al alumno tomar decisiones en los más variados contextos del proceso de trabajo en salud de forma autónoma y reflexiva. Las autoras aun proponen algunas directivas para la enseñanza de la ética em el Pregrado de Enfermería: Transversalidad de la Enseñanza de la Ética/Bioética; Valores/Virtudes/ Actitudes éticas a ser desarrolladas por los alumnos; Fundamentación de la enseñanza de la ética/bioética en referenciales consistentes y docentes capacitados; Métodos y Estrategias activas de enseñanza-aprendizaje; Proceso participativo en la construcción de la enseñanza transversal de la ética/bioética.

Descriptores: Ética; Bioética; Programas de Pregrado en enfermería/ética; Directivas; Educación en Enfermería/ética; Enseñanza

\footnotetext{
* Trabalho elaborado a partir da tese de Doutorado apresentada à Universidade Federal de São Paulo UNIFESP - São Paulo (SP), Brasil.

${ }^{1}$ Professora do Colegiado de Enfermagem do Centro Universitário Filadélfia de Londrina - UniFil. Coordenadora do Comitê de Ética em Pesquisa com Seres Humanos da UniFil. Londrina (PR), Brasil.

${ }^{2}$ Professora Associada Adjunto do Departamento de Enfermagem da Universidade Federal de São Paulo - UNIFESP - São Paulo (SP), Brasil.
} 


\section{INTRODUÇÃO}

O ensino da Ética nas escolas de Enfermagem em nosso país tem se caracterizado por uma visão deontológica, determinado por uma orientação prescritiva e normativa, restrita a um conjunto de normas e códigos trabalhados teórica e abstratamente ${ }^{(1-2)}$.

A educação ética embasada somente em discussões conceituais não é suficiente para formar os profissionais que o momento atual exige. Um novo paradigma em saúde se estabeleceu na América Latina e tem-se discutido intensivamente a necessidade de mudança nas metodologias de formação dos profissionais da saúde. Um novo modelo de saúde exige novos sujeitos sociais, novas formas de prestação de serviços e novas maneiras de formar os profissionais da área ${ }^{(3)}$.

O perfil desejado dos egressos dos Cursos de Graduação em Enfermagem, no Brasil, remete-se a um profissional capaz de intervir nos serviços de saúde de baixa, média e alta complexidade. Por um lado, a tecnociência centrada nos hospitais e nos centros de diagnóstico de alta complexidade; por outro, a fome, a miséria, a injustiça, a corrupção política, a alocação de recursos e a distribuição dos serviços de saúde colocam o enfermeiro em um contexto dicotomizado, que exige desse profissional senso crítico para tomar decisões éticas e morais.

O pluralismo da sociedade humana atual, a complexidade dos problemas de saúde e a sofisticação da tecnologia impõem ao sistema educacional a necessidade de se repensar a sua função como agente facilitador e promotor do desenvolvimento da capacidade do aluno para tomar decisões. Nesse contexto, a tomada de decisão dos profissionais da saúde pode estar relacionada a questões de ordem técnica, científica, social e ética. Por isso, o enfermeiro precisa estar capacitado a articular conhecimentos, habilidades e valores.

Os conflitos vividos pelos enfermeiros podem ser divididos em dois planos: os conflitos relacionados ao desenvolvimento científico e tecnológico e os conflitos persistentes, que dizem respeito à equidade em saúde, etnia, sexo, serviços de saúde mal distribuídos, dentre outros. Por isso, os projetos de currículos de cursos de graduação em Enfermagem devem redimensionar a arte de ensinar e aprender Ética. Uma nova disciplina e somente mudanças programáticas não serão suficientes para um ensino com perspectivas renovadas.

Vivenciamos um período em que há necessidade de mudanças profundas no aparelho formador dos profissionais da saúde, porque o atual, individualista e antropocêntrico, não atende mais às necessidades das pessoas nem do processo de trabalho em saúde. As metodologias para se formar o(a) enfermeiro(a) exigem reorientações educacionais que facilitem a reflexão, o debate e a aplicação cotidiana da Ética no trabalho de ensinar e fazer enfermagem. A educação moral precisa ajudar o aluno a "analisar criticamente a realidade quotidiana e as normas sociomorais vigentes, de modo que contribua para idealizar formas mais justas e adequadas de convivência"(4). O indivíduo precisa não só se tornar capaz de conviver em uma sociedade pluralista e democrática, buscando estabelecer e favorecer relações mais justas na sociedade, mas, ao mesmo tempo também, ser capaz de raciocinar de forma autônoma ${ }^{(5)}$. Diante do desafio imposto pela diversidade e pluralidade cultural e moral, resta-nos arriscar na elaboração de propostas para uma educação moral das futuras enfermeiros(as) que possam favorecer ou contribuir para o desenvolvimento da capacidade de raciocinarem e julgarem questões morais.

\section{Diretrizes para o Ensino da Ética na Graduação EM ENFERMagem}

\section{Transversalidade do Ensino da Ética / Bioética} - Partindo-se do princípio de que o objetivo do ensino da Ética é o desenvolvimento moral do aluno, observase que uma única disciplina não consegue oferecer todos os recursos necessários para que tal meta seja atingida, pois estamos falando de um processo de longo prazo, complexo e abrangente. Uma das estratégias sugeridas para a inclusão do ensino da Ética na elaboração dos currículos é a abordagem transversal ${ }^{(4,5)}$, ou seja, as diversas áreas curriculares devem planejar atividades para a educação moral. A educação para a formação ética como transversal, inserida em todas as disciplinas/ módulos/unidades de um currículo não exime os educadores de pensarem em metodologias específicas e estratégias de ensino que promovam a reflexão dialógica. A transversalidade do ensino da Ética não pode recair em atividades desordenadas e ocasionais. O currículo, em sua totalidade, precisa conter um planejamento desse ensino do primeiro ao último ano: orientado por uma proposta suficientemente precisa e convenientemente seqüenciada ${ }^{(4)}$ de objetivos e desempenhos a serem alcançados, de conteúdos referentes a fatos e articulados com o processo de trabalho, além da práxis, procedimentos e valores.

Os Valores / Virtudes / Atitudes Éticas - Os valores a serem desenvolvidos pelos alunos precisam estar explícitos no Projeto Pedagógico do Curso, mas não de forma absoluta. Os conteúdos devem articular-se dialeticamente com o cotidiano, para provocar conflitos epistemológicos com a práxis e, então, estimular os alunos à reflexão crítica. $\mathrm{O}$ desenvolvimento da capacidade de raciocinar e julgar questões éticas pressupõe uma atitude moral reflexiva e autônoma. Portanto, é preciso renunciar 
estratégias de imposição de valores.

A exposição e discussão de uma amplitude de valores facilitarão ao aluno conhecê-los, e a tomar consciência de um conjunto de princípios que lhe sejam pessoais e que, possivelmente, se modificarão em decorrência das experiências a que estará sujeito ao longo de sua existência, incluindo a própria vida profissional. Apesar de alguns autores $^{(5)}$ afirmarem que não é papel da escola definir os valores que devem ser ensinados, outros ${ }^{(4)}$ sugerem que princípios universais como justiça, liberdade, igualdade, solidariedade, benevolência, tolerância, respeito, participação, compromisso e cooperação devem ser reforçados junto aos alunos. Nesse campo, podemos dizer que os princípios do Sistema Único de Saúde são princípios éticos, que precisam ser intensamente discutidos e confrontados com a práxis em saúde no nosso país: a saúde como um direito universal, a democratização do acesso aos serviços de saúde (igualdade na assistência à saúde, sem preconceitos ou privilégios de qualquer espécie), a universalização da assistência, a integralidade dos cuidados assistenciais, a preservação da autonomia das pessoas na defesa de sua integridade física e moral ${ }^{(6)}$. Outros valores baseados em uma perspectiva microética ou privada ainda podem ser trabalhados: a renúncia, o reconhecimento, a verdade, a abertura para com as pessoas, a empatia, a consideração, o amor, a coerência, a responsabilidade, o desejo de valor ${ }^{(4)}$. Ambos os espaços éticos apresentam como valores comuns a autonomia e a crítica. Um detalhe importante: os valores explícitos no currículo formal precisam estar presentes na atitude dos docentes diante das situações concretas vivenciadas nos espaços pedagógicos, pois o exemplo também é uma estratégia de ensino que favorece o desenvolvimento moral do educando.

Referencial / Fundamentação do ensino da Ética / Bioética-A fundamentação para os questionamentos e possíveis respostas relacionadas ao desenvolvimento moral precisa estar alicerçada na Pedagogia, na Psicologia, na Sociologia e na Filosofia. A Bioética emergiu como um movimento interdisciplinar para questionar e refletir sobre as questões concretas que a sociedade atual está vivenciando. A sustentabilidade do planeta, a natureza e a dignidade humana, a biotecnologia e outras temáticas, que interferem no processo saúde-doença, ultrapassam qualquer fronteira que limite áreas específicas do conhecimento. Por isso, o ensino baseado somente em questões inerentes à prática de enfermagem não é capaz de desafiar os educandos a refletirem, com profundidade, sobre o seu desenvolvimento moral

Pelo fato de a Bioética ser, por um lado, um tema que mobiliza as pessoas de maneira geral e, por outro, pode envolver conflitos e interesses diversos, muitos profissionais consideram-se aptos a discutir e a ensinar
Bioética ${ }^{(7)}$. Tal afirmação é comprovada quando observamos que, nos cursos de graduação em Enfermagem no Brasil, qualquer docente, de qualquer área, assume a disciplina de Ética e/ou Bioética quando não se dispõe de profissional habilitado. É uma das poucas disciplinas dos Cursos de Graduação em Enfermagem para a qual não se exige um especialista na área. Entretanto, apesar de ser a ética uma avaliação de consciência individual, sobre a adequação de costumes (moral) e leis ou normas (legais), é necessária uma fundamentação teórica mínima que possa representar, antes de um bom senso individual, um bom senso comum, à luz de princípios e valores morais defensáveis ${ }^{(7)}$. Além de fundamentação teórica, destacam-se três características essenciais para um professor de Bioética: uma pessoa deliberada, mas com uma prática constante de reflexão baseada em fundamentação teórica; prudência na tomada de decisões; tolerância com os princípios e valores das pessoas envolvidas em situações que envolvem aspectos éticos ${ }^{(7)}$.

Os programas de graduação em Enfermagem que propõem a Ética e a Bioética como tema transversal, porque pretendem discutir o assunto em todas as disciplinas, ou unidades, ou módulos do currículo, podem propiciar aos docentes a oportunidade de desafiar os alunos à reflexão. Entretanto, é preciso garantir que a condução do debate e a elaboração de valores/princípios pelos alunos sejam facilitados por um professor com fundamentação teórica em Ética e Bioética.

Os Métodos e as Estratégias de Ensino não podem consolidar uma prática de transmissão de valores e normas a serem respeitadas e cumpridas pelos alunos. Os contextos, os conflitos de convivência e de trabalho devem ser o pano de fundo do ensino e da aprendizagem da ética, sobre o qual os alunos e os professores estabelecem o diálogo. As experiências reais e diretas da vida coletiva e do processo de trabalho em saúde são os contextos em que o ensino e a aprendizagem da Ética se dão de maneira mais eficaz. Por isso, é importante que se tenha um ambiente em que a Ética e a prática da Ética seja uma realidade.

Apesar de a Problematização e de a Aprendizagem Baseada em Problemas serem citadas como modelos de ensino eficazes, para a formação moral é preciso que os educadores fundamentem sua prática em uma determinada epistemologia ou teoria do conhecimento. Não basta adotar metodologias e meios inovadores, se o docente não tiver uma concepção pedagógica estruturada para fundamentar e direcionar sua prática educativa.

Pensar em métodos e instrumentos de ensino implica 
uma reflexão teórica consistente sobre o processo de aprender e, para tanto, os conceitos centrais da Psicologia Genética de Jean Piaget são de grande contribuição. Segundo Piaget, o ser humano desenvolve formas de ação para conhecer alguma coisa, variando desde formas externas e visíveis, quando manipula objetos e interage com a natureza, como internas e não visíveis, descritas como operações mentais. Segundo a Psicologia, a conduta moral e a competência ética são questões decorrentes do próprio desenvolvimento sociocognitivo do ser humano no seu meio, na sua cultura. O julgamento moral e o comportamento moral são uma questão de desenvolvimento cognitivo que necessita de maturação biológica das estruturas mentais, assim como da qualidade de interação do ser humano com o seu meio como desenvolvimento psicossocial ${ }^{(8)}$. Portanto, é possível compreender que a aprendizagem para o desenvolvimento moral encontra fundamentos nas teorias psicológicas interacionistas e socioculturais, por explicarem que as aprendizagens derivam da interação entre o sujeito que aprende e o objeto do conhecimento, em um determinado ambiente cultural.

A compreensão de que o conhecimento se concretiza por meio das representações mentais que o sujeito estabelece a partir de sua relação com o objeto e deste com os outros objetos, leva-nos a afirmar que a problematização, enquanto categoria de construção de conhecimento, é uma alternativa viável para o ensino da Ética/Bioética. A problematização pressupõe experimentação, trabalho em grupo e pesquisa como elementos de provocação, de desafio, de significação para diversas atividades pedagógicas ${ }^{(9)}$.

\footnotetext{
A transversalidade do ensino da Ética / Bioética no Curso de Graduação em Enfermagem deve ser produto de um processo participativo, envolvendo ativamente professores, alunos, profissionais da saúde e representantes dos usuários dos serviços de saúde. Oficinas para revisão e reformulação de conceitos relacionados à Ética e à Bioética são imprescindíveis e, além disso, conceitos pedagógicos precisam ser amplamente discutidos para a transformação da práxis e para o resgate do verdadeiro sentido da enfermagem: o respeito à vida do ser humano.
}

\section{CONSIDERAÇÕES FINAIS}

Escrever em poucas páginas sobre a temática deste artigo foi uma tarefa desafiadora, pois as questões envolvidas no processo ensino-aprendizagem da ética são extremamente complexas, porque têm sua origem no objeto em que se estabelecem todas as relações pedagógicas do curso: o Currículo. Ademais, as reflexões representam, não apenas a síntese de anos de investigação sobre os fundamentos e a práxis do processo ensinoaprendizagem, mas também sobre a ética e a bioética.

Nossa proposta de redirecionar o ensino da ética em enfermagem de um enfoque deontológico centrado em discussões conceituais, para um ensino transversal de valores, por meio de metodologias ativas, exige de todos os envolvidos no processo ensino-aprendizagem uma postura inovadora que desencadeie uma nova prática. Mas, para que isso se concretize, é preciso desejar, pensar e planejar uma educação intencionalizada que considere o vir-a-ser do aluno, cujo núcleo da formação do(a) enfermeiro(a) não seja somente os meios e os conteúdos, e sim a pessoa humana. Cabe ressaltar, também, a necessidade de se enfrentar o ensino metafísico da ética e da bioética administrando cursos diferentes, pessoas e posturas diferentes que levem ao planejamento e implementação de projetos de educação em enfermagem para que integrem o ensino à realidade.

É nosso propósito, com essas reflexões, fomentar uma educação em enfermagem que envolva o espírito crítico e a capacidade de dialogar, de buscar a justiça, a solidariedade, a igualdade e a coerência entre os meios e os fins.

\section{REFERÊNCIAS}

1. Germano RM. A ética e o ensino de ética na enfermagem do Brasil. São Paulo: Cortez; 1993.

2. Gomes PC. Ética e enfermagem: relações ou reações? [ Tese Doutorado ]. São Paulo: Escola Paulista de Medicina da Universidade Federal de São Paulo; 1999.

3. Almeida M, Feuerwerker L, Llanos C M (Organizadores). A educação dos profissionais de saúde na América Latina: teoria e prática de um movimento de mudança. São Paulo; Buenos Aires: Hucitec: Lugar Editorial; 1999.

4. Puig JM. Ética e valores: métodos para um ensino transversal. São Paulo: Casa do Psicólogo; 1998.

5. Rego S. A formação ética dos médicos: saindo da adolescência com a vida (dos outros) nas mãos. Rio de Janeiro: Editora Fiocruz; 2003.

6. Figueiredo NMA, organizador. Ensinando a cuidar em saúde pública. São Caetano do Sul: Yendis; 2005.

7. Kipper DJ. Docentes de bioética: critérios de certificação e qualificação. In: $6^{\circ}$. Congresso Brasileiro de Bioética, 2005, Foz do Iguaçu. Anais. São Paulo: Loyola ; 2005. p. 20.

8. Piaget J. Le Jugement moral chez L'enfant. Paris: Librairie Felix Alcan; 1932.

9. Diaz Bordenave J, Pereira AM. Estratégias de ensinoaprendizagem. 8a ed. Petrópolis; (RJ): Vozes; 1986. 